\title{
Therapeutic approach for gingival smile treatment
}

\author{
Radostina Vasileva ${ }^{1}$
}

1. Department of dental material science and propaedeutic of prosthetic dental medicine, Faculty of dental medicine, Medical university Varna;

\begin{abstract}
Nowadays patients often look for dental services because of aesthetic reasons. One of the aesthetic problems is the gingival smile - i.e. the excessive exposure of the gingiva while smiling. The major etiological factors associated with gingival smile include: passive exposure, vertical maxillary surge, hyper function of the upper lip muscles and / or a combination of them. This condition has a psychological impact on some patients, resulting in inconvenience, a feeling of unattractiveness and dissatisfaction. The methods for treating gingival smiles are invasive varieties of surgical approaches and non-invasive by botox therapy.
\end{abstract}

Purpose: The purpose of this article is to carry out a unified review of scientific evidences, literature related to the methods used in the treatment of gingival smile, as well as identifying the best correction technique with a long-term predictability of the procedure.

Materials and Methods: After analyzing the scientific literature from the databases Web of Science PubMed, Scopus and others, it was found that in most of the cases were examined women whose mean age is under 30 years. In most of the articles predominate reports involving invasive methods, but insufficient datas for a long-term predictability and post-treatment follow-up.

Conclusion: This article found a serious lack of controlled and randomized clinical trials in the use of periodontal surgical methods of treatment of gingival smile and stresses the need for clinical follow-up studies with more evidences in order to establish the best type of periodontal surgery for this purpose.

Keywords: Botox, Gummy smile, excessive gingival display on smiling, treatment gummy smile 


\section{Introduction}

Nowadays patients often look for dental services not only for health reasons, but also for aesthetic reasons in order to achieve more harmonious and symmetrical smiles. The smile of the patient is a kind of emotional tool, a form of communication; attraction and type of socialization. (1) The main task of dental doctors is not only to restore the function, but also to provide satisfaction for the patients after the dental rehabilitation. (2) The harmonization of the aesthetic smile requires precise integration of the teeth and the teeth rows in a moment of rest and in the dynamic of the mimic muscles, tailored to the face shape and the preference of the patient. However, on one hand, still part of the dentists neglect the key moments in their planning of the smile patterns. On the other hand, the harmony of the smile is determined not only by its shape, its position and the color of the teeth, the shape of the frame, but also by the exposure, the morphology and the contour of the gingiva. The presence of excessive visualization of gingivitis in a smile is accepted as a compromise and an unsatisfactory aesthetic result. Today browsing the essence of the smile, we necessarily include an analysis of three main components: teeth, the frame outlined by the lips at a smile and the gingival exposure. $(1,2,3,4,5,6,7)$

The violations that compromise the aesthetic of the smile, associated with the greater visualization of the gingiva, are a medical condition known as "gummy smile." (6.7). The perception of gingival exposure values is a question of cultural, ethnic, age and gender characteristics, as well as personal preferences. According to Allen (USA), the exposure of the gingiva (below 2-3 $\mathrm{mm}$ ) could be counted for acceptable and relatively aesthetic state, while overexposure (over $3 \mathrm{~mm}$ ) is considered unattractive and an aesthetic problem. $(6,8,9,10,11)$ Unlike from the United States in some parts of Europe, the allowed norms may exceed those values and reach acceptable $4 \mathrm{~mm}$ range. (10) While these values of 3 or $4 \mathrm{~mm}$ are accepted for women, only men are expected to have exposure of the frontal teeth. The effects of age lead to the loss of muscle tone, which results in a lower visibility of the upper teeth, respectively of the gingiva and the tendency to increased exposure to lower teeth. $(3,4)$ The gingival smile is recognized by the American Academy of Parodontology (AAP), such as deformation and mucosalgic condition affecting the around teeth area. (10) The sexual dimorphism indicates that a gingival smile is more common in women $-10 \%$ of them being registered among the population between age of 20 and 30. (12)

In order to establish a correct diagnosis, the exact classification of the gingival level is needed, taking into account the factors - sex, age and periodontal health. After finding an anomaly in the level of the gingiva in a smile is essentially significant to define her etiology. Typically, this condition is multifactorial, associated with excessive vertical growth of the maxilla, reduced length of the top lips, excessive contraction of the mimic muscles of the upper lip, a disproportionate length and width of the frontal teeth or extrusion of the teeth associated with a deep bite. $(12,13,14,15,16,17)$ Taking into account the etiology of the gingival smile, the correct diagnosis on which they are based, will be established therapeutic approaches for treatment and correction of the gingival smile.

In clinical / photographic review, images need to be included in spontaneous and exaggerated smile, video documentation and long - term surveillance expression of the patient, subject to the conditions of isometricity. Some authors recommend radiographic analysis, Ricketts cephalometric analysis, the use of computed tomography. The therapeutic treatment procedure will depend on the etiology, the severity of the case, the age of the patient. $(18,19,20,21,25,26,27)$ 
Therapeutic approaches: The main therapeutic approaches, according to the etiology, can conditionally be divided into dental, gingival, bone and muscle approaches etiology. $(22,23)$

In dental etiology there is an excessive extrusion of the upper incisors, which can be treated by intrusive mechanical methods. In this case the problem is limited to the frontal area. In patients with gingival etiology gingivectomy operative interventions are applied. In bone etiology, characterized by a vertical maximal surplus occurring predominantly in patients with predominantly vertical growth should be applied surgical oprogenic interventions.

Muscle relaxation and frenectomy are most often indicated for short upper lip, determined by the Ricketts cephalometric analysis. The use of botulinum toxin (Botox) is indicated in cases of hypercontraction of levator labii superioris, determined by eliminating other etiologies. (1,6,9,14 and others), treatment by infiltration into the paranasal region with a hyaluronic technology filler. (24) The objective of this article is to carry out an unified review of scientific evidence, literature related to the methods used in the treatment of gingival smile, identifying the most appropriate correction and long-term techniques predictability of the results of the procedures, used by conservative and invasive therapeutic approches for the treatment of the GS.

\section{Aim}

The purpose of this article is to carry out a unified review of scientific evidences, literature related to the methods used in the treatment of gingival smile, as well as identifying the best correction technique with a long-term predictability of the procedure.

\section{Material and methods}

The literary survey was conducted in the first quarter of 2019. The information was gathered manually and electronically as they were used the scientific databases of PubMed, ResearchGate and others. The search included the key words: gummy smile treatment; Excessive gingival display on smiling; botox gummy smile, crown lengthening, gingivectomy, surgery, plastic etc. After selecting the titles, the abstracts and the conclusions, were selected texts containing information about diagnostics, treatment methods, follow-up results and conclusions.

\section{Results}

The tabular figure lists the data that includes methods of etiological treatment, the variability of the techniques used, the results achieved, the long-term stability of the achieved results. Among the patients seeking GS treatment, after the trials screening studies, the authors found that the hypercontraction of levator labii superioris is the most prevalent etiology of $45.3 \%$, but is also common in combination with altered passive eruption APE 34\%. (25) Based on this study, those searched results were divided into three groups of etiological treatment methods.(Table 1) A total of 74 publications were reviewed, of which 65 were selected. 
Tabl.1 Results divided in three groups of etiological treatment methods

\begin{tabular}{|l|c|c|c|}
\hline $\begin{array}{c}\text { Methods for etiological } \\
\text { treatment }\end{array}$ & $\begin{array}{c}\text { Variability of the } \\
\text { used } \\
\text { techniques }\end{array}$ & $\begin{array}{c}\text { Achieved } \\
\text { results }\end{array}$ & $\begin{array}{c}\text { Long-term } \\
\text { stability } \\
\text { of the } \\
\text { achieved } \\
\text { results }\end{array}$ \\
\hline 1. Dental, gingival, bone & + & + & + \\
\hline 2. Muscular etiology & +++ & + & ++ \\
\hline 3. Combined & + & + & - \\
\hline
\end{tabular}

The articles were dominated by clinical reports, two reports and were found two randomized controlled trials of surgical periodontal methods for treatment. The longest period of follow-up is the treatment of the GS of orthodontic etiological indicator is 21 months and oprogenic and periodontal surgery methods of maximum 6 to 12 months. $(32,33,47,48$, etc.) Only in one report has been reported about lips repositioning as an alternative to the invasive surgery with satisfactory results that are stable for 4 years. (37)

All reports show patient satisfaction after treatment and positive aesthetic result. In the examined literature is identified the genetic predisposition and dysplasia of the nasal septum as an etiological factor. The predominant papers that comment on the surgical methods are mainly with myotomy, upper lip reposition, gingiviectomy with osteotomy. The current trend discussed in most of the articles regards less invasive botulinum toxin techniques. All related articles with relaxation of the muscles by botox are a clinical case and all of them indicate satisfaction, lack of post-operative complications but short-term effect.

\section{Discussion}

Ishida $Y$ and Ono T., describe GS effective alternative treatment for improving a gummy smile in a patient with a severe Class II molar relationship, severe crowding, and lip protrusion using zygomatic anchorage devices and improved superelastic nickel-titanium wires; alternative treatment option to orthognathic surgery for adults with high-angle skeletal Class II malocclusion and a gummy smile. (28)

In cases of GS from dental, gingival, bone etiological treatment, the periodontal doctor is a leading specialist. Clinical examination and radiographic evaluation will allow clinicians to determine the position of the gingival margin, bone crest and cemento-enamel junction and thus cause a correct diagnosis of the subtype of altered eruption. The periodontist will need to consider these factors in order to obtain a satisfactory result, especially in multidisciplinary cases. (29). When treating a gingival smile with muscular etiology, mood and treatment with oral or reconstructive surgery, repositioning lips as an alternative to invasive surgery with satisfactory results that are stable for 4 years. (37) Alammar AM, Heshmeh OA. Repositioning of lips is an effective method of treating EGD, however, the detachment of the muscle provides a more stable result for 12 months than the classic technique. According to them, more studies are needed to fully evaluate this procedure. $(35,40)$ Classical predictive techniques for lip and laser extension of the crown in vertical 
maxillary cases, describes Ramesh $\mathrm{Al}$, in a series of cases they point to the predictability of the technique of repositioning of the lips with 2 years CR follow-up. (57)

The botox approach requires quality assessment to determine the level of the evidence and the deviations, and to perform a meta-analysis. There are really weak evidences to be determined the duration of effectiveness of toxin of type A on GS. The effect is stable to at least 8 weeks of follow-up and t hgingival exposure may not return to the baseline within 12 weeks of the tracking. For strengthening the evidences are required well-developed randomized clinical trials tests with a minimum of 6 months of follow - up. (45) The combined gingivectomy and the botox injection technique in heavy-duty management of the GS could be appropriate (59)

The micro-autologous fat transplantation (MAFT) is a potential alternative approach. Huang Sheet al. examined seven patients with GS treated with MAFT between October 2015 and April 2017. In their study they seek to determine long-term results of the MAFT. The centrifuged purified fat microtransplants in the nasolabial groove, ergotrid and the upper lip areas using MAFT-GUN while patients were under general intravenous anesthesia. The average age of the 7 patients is 31 years (range 23-40 years). The average MAFT's operating time is 52 minutes (range: 40-72 minutes), and the average volume of the fat delivered in the nasolabial groove, ergotrid and upper lip is $16.1 \mathrm{ml}$. (46) The smiles of the 7 patients showed significant improvement at mean time follow-up of 12.9 months. Outputs: According to Huang Sheet al. treatment of GS, using MAFT is an efficient, reliable and relatively simple method, high patient satisfaction and minimal risk of complications. Except the main approaches focused on the individual etiology from bone, dental, muscle, soft tissue and their combination, Wei $\mathrm{J}$ et al. also indicate the identification of nasal dysplasia as etiologic GS factor. $(63,64)$ In a controlled study of 46 patients with significantly increased columella upward maximum movablity, underwent surgical treatment for excessive gingival exposure by septum cartilage reinforcement and, where required, additional extension using an autologous graft or an expanded cartilage polytetrafluoroethylene implant. In the 46 patients undergoing surgical GS correction, Wei $\mathrm{J}$ et al., established the measured maximum exposure of the gingiva in a maximum complete smile was $4.52 \pm 1.7 \mathrm{~mm}$ before surgery and significantly reduced to $1.79 \pm 0.26 \mathrm{~mm}$ at 6 months post-operative state $(p<0.05) .(63)$

There is no standardized minimally invasive approach to GS treatment. The Botulinum toxin injection is a new, safe and cosmetically effective treatment for a sticky smile when done by experienced practitioners. However it is required a further randomized controlled trial. Level of proof 4: Therapeutic. (12)

The use of a digital smile design has emerged as a powerful tool in the cosmetic dentistry to help the practitioner and the patient to visualize the end result. (65)

\section{Conclusion}

The etiology of the gingival smile dictates the most appropriate treatment approach. The need for accurate diagnosis, specialized communication and the complex plan of modern alternative treatment of the therapeutic processes are important factors for achieving a predictable aesthetic result.

There is no standardized minimally invasive approach to treat the GS, but an increasing demand is recognized for less invasive techniques - for example - interventions associated with the injection of 
botulinum toxin and the micro-autologous fat transplantation. Although the reported positive results are required additional controlled clinical trials.

After a thorough analysis of the articles, it was found that there was not enough clinical controlled and randomized evidences, and multiple studies for both invasive and non-invasive methods for GS treatment. The main findings relate to patient satisfaction after interventions. The average age of the patients, undergoing periodontal surgery: predominantly young people. This may be related to the aesthetic needs of individuals of that age and to the fact that the condition of a gummed smile gradually decreases with age due to the upper and the lower motility of the oral cavity, which in turn leads to a reduction of the exposure of the upper incisors of the elderly patients. In all studies, women are predominant, because of the greater aesthetic need among women, especially in terms of an attractive smile.

\section{References}

1. Oliveira MT. Molina GO. Furtado A. Ghizoni JS. Pereira JR. Gummy smile: A contemporary and multidisciplinary overview, Dental Hypotheses Apr-Jun 2013 / Vol 4.

2. Magne $P$, Belser U. Bonded porcelain restorations in the anterior dentition. Carol Stream (IL); Quintessence Int, 2004: 58-64.

3. Vig RG, Brundo GC. The kinetics of anterior tooth display. J Prosthet Dent 1978;39:502-4.

4. Peck S, Peck L, Kataja M. Some vertical lineaments of lip position. Am J Orthod Dentofacial Orthop 1992;101:519-24.

5. Nicholas C. Davis. Smile Design. Dent Clin N Am 51 (2007) 299-318

6. Dayanne Moura1, Emanuelle Lima1, Ruthinéia Lins2, Rodrigo Souza2, Ana Martins2, Bruno Gurgel2. The treatment of gummy smile: integrative review of literature. Rev. Clin. Periodoncia Implantol. Rehabil. Oral Vol. 10(1); 26-28, 2017.

7. Coslet JG, Vanarsdall R, Weisgold A. Diagnosis and classification of delayed eruption of the dentogengival junction in the adult. Alpha Omegan 1977; 70(3): 24-28.

8. Allen EP. Use of mucogingival surgical procedures to enhance esthetics. DentClin North Am 1988; 32:307-30

9. Abou-Arraj RV, Souccar NM. Periodontal treatment of excessive gingival display. Seminars in Orthodontics, Vol19, N4 (December), 2013:pp267-278.

10. Armitage, GC. Development of a classification system for periodontal diseases and conditions. Annals of periodontology / the American Academy of Periodontology,4 (1999), pp. 1-6

11. Jensen J, Joss A, Lang NP. The smile line of different ethnic groups in relation to age and gender. Acta Med Dent Healv 1999;4:38-46

12. Tjan AH, Miller GD, The JG. Some esthetic factors in a smile. J ProsthetDent 1984;51:248.

13. Reddy PK, Nayak DG, Uppoor A. Aesthetic crown lengthening: A report of 3 cases. Malay Dent J 2006;1:110-3.

14. Monaco A, Streni O, Marci MC, Marzo G, Gatto R, Giannoni M. Gummy smile: Clinical parameters useful for diagnosis and therapeutical approach. J Clin Pediatr Dent 2004;29:1925.

15. Hwang WS, Hur MS, Hu KS, Song WC, Koh KS, Baik HS, et al. Surface anatomy of the lip elevator muscles for the treatment of gummy smile using botulinum toxin. Angle Orthod 2009;79:70-7.

16. Lin JC, Yeh CL, Liou EJ, Bowman SJ. Treatment of skeletal-origin gummy smiles with miniscrew anchorage. J Clin Orthod 2008;42:285-96.

17. Kim TW, Kim H, Lee SJ. Correction of deep overbite and gummy smile by using a mini-implant with a segmented wire in a growing Class II Division 2 patient. Am J Orthod Dentofacial Orthop 2006;130:676-85 
18. Ferrario VF, Sforza C, Schimitz JH, Ciusa V, Dellavia C. Digitized three-dimensional analysis of normal dento-labial relationships. Prog Orthod 2001;2:232-4.

19. Van der Geld P, Oosterveld P, Kuijpers-Jagtman AM. Age-related changes of the dental aesthetic zone at rest and during spontaneous smiling and speech. Eur J Orthod 2008;30:366 73.

20. Levine RA., McGuire, M. The diagnosis and treatment of the gummy smile. Europe PMC. 1997. 18(8):757-62.

21. Alpiste-Illueca, F. Dimensions of the Dentogingival Unit in Maxillary Anterior Teeth: A New Exploration Technique (Parallel Profile Radiograph). International Journal of Periodontics \& Restorative Dentistry. 2004, 24 (4): 386-396.

22. Robbins JW1. Differential diagnosis and treatment of excess gingival display. Pract Periodontics Aesthet Dent. 1999 Mar;11(2):265-72; quiz 273.

23. Silberberg N1, Goldstein M, Smidt A. Excessive gingival display--etiology, diagnosis, and treatment modalities. Quintessence Int. 2009 Nov-Dec;40(10):809-18.

24. Diaspro A, Cavallini M, Patrizia P, Sito G. Gummy Smile Treatment: Proposal for a Novel Corrective Technique and a Review of the Literature. Aesthet Surg J. 2018 Nov 12;38(12):13301338.

25. Andijani RI1, Tatakis DN1. Hypermobile upper lip is highly prevalent among patients seeking treatment for gummy smile. J Periodontol. 2019 Mar;90(3):256-262. doi: 10.1002/JPER.180468. Epub 2018 Nov 21.

26. Livada R, Shiloah J. Gummy smile: could it be genetic? Hereditary gingival fibromatosis. J Mich Dent Assoc. 2012 Dec;94(12):40-3.

27. De Rouck, T., Eghbali, R., Collys, K., De Bruyn, H., Cosyn, J. The gingival biotyperevisited: transparency of the periodontal probe through the gingival margin asa method to discriminate thin from thick gingiva. Journal of clinical Periodontology.2009. 36(5):428-433.

28. Ishida Y1, Ono T2. Nonsurgical treatment of an adult with a skeletal Class II gummy smile using zygomatic temporary anchorage devices and improved superelastic nickel-titanium alloy wires. Am J Orthod Dentofacial Orthop. 2017 Nov;152(5):693-705. doi: 10.1016/j.ajodo.2016.09.030.

29. Verardi S1, Ghassemian M2, Bazzucchi A3, Pavone AF4. Gummy Smile and Short Tooth Syndrome - Part 2: Periodontal Surgical Approaches in Interdisciplinary Treatment. Compend Contin Educ Dent. 2016 Apr;37(4):247-251

30. Hong RK1, Lim SM, Heo JM, Baek SH. Orthodontic treatment of gummy smile by maxillary total intrusion with a midpalatal absolute anchorage system. Korean J Orthod. 2013 Jun;43(3):14758. doi: 10.4041/kjod.2013.43.3.147. Epub 2013 Jun 24.

31. Kim TW, Kim H, Lee SJ. Correction of deep overbite and gummy smile by using a mini-implant with a segmented wire in a growing Class II Division 2 patient. Am J Orthod Dentofacial Orthop. 2006 Nov;130(5):676-85

32. Fowler P. Orthodontics and orthognathic surgery in the combined treatment of an excessively "gummy smile". N Z Dent J. 1999 Jun;95(420):53-4.

33. Kao RT1, Dault S, Frangadakis K, Salehieh JJ Esthetic crown lengthening: appropriate diagnosis for achieving gingival balance. J Calif Dent Assoc. 2008 Mar;36(3):187-91.

34. Alpiste-Illueca F1. Altered passive eruption (APE): a little-known clinical situation. Med Oral Patol Oral Cir Bucal. 2011 Jan 1;16(1):e100-4.

35. Kaku M1, Kojima S, Sumi H, Koseki H, Abedini S, Motokawa M, Fujita T, Ohtani J, Kawata T, Tanne K. Gummy smile and facial profile correction using miniscrew anchorage. Angle Orthod. 2012 Jan;82(1):170-7. doi: 10.2319/020711-86.1

36. Storrer CL, Valverde FK, Santos FR, Deliberador TM. Treatment of gummy smile: Gingival recontouring with the containment of the elevator muscle of the upper lip and wing of nose. A surgery innovation technique. J Indian Soc Periodontol 2014;18:656-60.

37. Foudah MA. Lip repositioning: An alternative to invasive surgery a 4 year follow up case report. The Saudi Dental Journal Volume 31, Supplement, 2019, Pages S78-S84

38. Duruel O, Ataman-Duruel ET, Berker E, Tözüm TF. Treatment of Various Types of Gummy Smile With Botulinum Toxin-A.J Craniofac Surg. 2019 May/Jun;30(3):876-878. 
39. Al Wayli H. Versatility of botulinum toxin at the Yonsei point for the treatment of gummy smile. Int J Esthet Dent. 2019;14(1):86-95.

40. Alammar AM, Heshmeh OA. Lip repositioning with a myotomy of the elevator muscles for the management of a gummy smile. Dent Med Probl. 2018 Jul-Sep;55(3):241-246. doi: $10.17219 / \mathrm{dmp} / 92317$.

41. Araujo JP1, Cruz J, Oliveira JX, Canto AM. Botulinum Toxin Type-A as an alternative treatment for gummy smile: a case report. Dermatol Online J. 2018 Jul 15;24(7). pii: 13030/qt75f0h8kz.

42. K D1, Yadalam U2, Ranjan R3, Narayan SJ2. Lip repositioning, an alternative treatment of gummy smile - A case report. J Oral Biol Craniofac Res. 2018 Sep-Dec;8(3):231-233. doi: 10.1016/j.jobcr.2017.09.007. Epub 2017 Sep 27.

43. Tawfik OK,Naiem SN, Tawfik LK, Yussif N, Meghil MM, Cutler CW, Darhous M1, El-Nahass HE1. Lip repositioning with or without myotomy: A randomized clinical trial. J Periodontol. 2018 Jul;89(7):815-823.

44. Faus-Matoses V1, Faus-Matoses I2, Jorques-Zafrilla A. Lip repositioning technique. A simple surgical procedure to improve the smile harmony. J Clin Exp Dent. 2018 Apr 1;10(4):e408e412. doi: 10.4317/jced.54721. eCollection 2018 Apr.

45. Chagas TF1, Almeida NV1, Lisboa CO1, Ferreira DMTP2, Mattos CT1, Mucha JN1. Duration of effectiveness of Botulinum toxin type $A$ in excessive gingival display: a systematic review and meta-analysis. Braz Oral Res. 2018;32:e30. doi: 10.1590/1807-3107bor-2018.vol32.0030. Epub 2018 May 7.

46. Huang SH, Huang YH, Lin YN, Lee SS, Chou CK, Lin TY, Takahashi H, Kuo YR, Lai CS, Lin SD, Lin TM. Micro-Autologous Fat Transplantation for Treating a Gummy Smile. Aesthet Surg J. 2018 Aug 16;38(9):925-937.

47. Nasr MW1, Jabbour SF1, Sidaoui JA1, Haber RN1, Kechichian EG Botulinum Toxin for the Treatment of Excessive Gingival Display: A Systematic Review. Aesthet Surg J. 2016 Jan;36(1):82-8. doi: 10.1093/asj/sjv082. Epub 2015 Aug 7.

48. Abdullah WA1, Khalil HS2, Alhindi MM3, Marzook H4. Modifying gummy smile: a minimally invasive approach. J Contemp Dent Pract. 2014 Nov 1;15(6):821-6.

49. Niamtu J 3 Botox injections for gummy smiles. Am J Orthod Dentofacial Orthop. 2008 Jun;133(6):782-3; author reply 783-4.

50. Hwang WS1, Hur MS, Hu KS, Song WC, Koh KS, Baik HS, Kim ST, Kim HJ, Lee KJ. Surface anatomy of the lip elevator muscles for the treatment of gummy smile using botulinum toxin. Angle Orthod. 2009 Jan;79(1):70-7.

51. Gracco A1, Tracey S. Botox and the gummy smile. Prog Orthod. 2010;11(1):76-82. doi: 10.1016/j.pio.2010.04.004. Epub 2010 May 25.

52. Sucupira E, Abramovitz A. A simplified method for smile enhancement: botulinum toxin injection for gummy smile. Plast Reconstr Surg. 2012 Sep;130(3):726-8.

53. Guo J, Gong H, Tian W, Tang W, Bai D. Alteration of gingival exposure and its aesthetic effect. J Craniofac Surg. 2011 May;22(3):909-13.

54. Sarita NTV, Narayan PC. Correction of gummy smile: A report of two cases. JIndian SocPeriodontol. 2011 Oct-Dec; 15(4): 421-424.

55. Roberto R, Remo B, Morales RIS. Treatment of Altered Passive Eruption: PeriodontalPlastic Surgery of the Dentogingival Junction. Eur J EsthetDent. 2008;3(3):212-23.

56. Cairo F, Graziani F, Franchi L, Defraia E, Prato GPP. 'Periodontal Plastic Surgeryto Improve Aesthetics in Patients with Altered Passive Eruption/Gummy Smile: ACase Series Study. International Journal of Dentistry. 2012.

57. Ramesh A1, Vellayappan R1, Ravi S1, Gurumoorthy K1. Esthetic lip repositioning: A cosmetic approach for correction of gummy smile - A case series. J Indian Soc Periodontol. 2019 MayJun;23(3):290-294. doi: 10.4103/jisp.jisp_548_18

58. Pedron IG1, Mangano A2. Gummy Smile Correction Using Botulinum Toxin With Respective Gingival Surgery. J Dent (Shiraz). 2018 Sep;19(3):248-252. 
59. Mostafa D1. A successful management of sever gummy smile using gingivectomy and botulinum toxin injection: A case report. Int J Surg Case Rep. 2018;42:169-174. doi: 10.1016/j.ijscr.2017.11.055. Epub 2017 Dec 1.

60. Bynum J1. Treatment of a "Gummy Smile": Understanding Etiology is Key to Success. Compend Contin Educ Dent. 2016 Feb;37(2):114-22.

61. Xie C, Meng Y. A Case Report of Esthetic and Functional Correction of Maxillary Protrusion Using a Prosthodontics-Centered Multidisciplinary Approach. Int J Periodontics Restorative Dent. 2016 Mar-Apr;36(2):e33-40. doi: 10.11607/prd.2034.

62. Ishida LH, Ishida LC, Ishida J, Grynglas J, Alonso N, Ferreira MC. Myotomy of the levator labii superioris muscle and lip repositioning: a combined approach for the correction of gummy smile. Plast Reconstr Surg. 2010 Sep;126(3):1014-9. d

63. Wei J1, Herrler T2, Xu H1, Li Q1, Dai C3. Treatment of gummy smile: Nasal septum dysplasia as etiologic factor and therapeutic target. J Plast Reconstr Aesthet Surg. 2015 Oct;68(10):133843. doi: 10.1016/j.bjps.2015.06.011. Epub 2015 Jun 24.

64. Polo M. Re: 'Treatment of gummy smile: Nasal septum dysplasia as etiologic factor and therapeutic target'. J Plast Reconstr Aesthet Surg. 20150ct;68(10):1344-5. doi: 10.1016/j.bjps.2015.07.012. Epub 2015 Jul 26.

65. Arias DM1, Trushkowsky RD2, Brea LM3, David SB3. Treatment of the Patient with Gummy Smile in Conjunction with Digital Smile Approach. Dent Clin North Am. 2015 Jul;59(3):703-16. doi: 10.1016/j.cden.2015.03.007.

\section{Corresponding author:}

Radostina Vasileva, Department of Dental Material Science and Propaedeutics of Prosthetic Dental Medicine, Faculty of Dental Medicine, Medical University Varna email: radost11dent@abv.bg 